\title{
Mechanical ond opto-chemical dating of the Turin Shroud
}

\author{
Giulio Fanti ${ }^{1}$, Pierandrea Malfi ${ }^{2}$, Fabio Crosilla $^{3}$ \\ ${ }^{1}$ Department of Industrial Engineering, Padua University, via Venezia 1, 35131 , Padova, Italy, giulio.fanti@unipd.it \\ ${ }^{2}$ CRIS (Committee for Engineering Research on the Turin Shroud), via G.L. Bernini 108/1, Mira, Venice, Italy, \\ malfipier@yahoo.it \\ ${ }^{3}$ Department of Civil Engineering and Architecture, University of Udine, via delle Scienze 206, 114 I-33100 Udine, \\ Italy fabio.crosilla@uniud.it
}

\begin{abstract}
The TS (Turin Shroud) is a linen cloth which enveloped the dead body of a tortured and crucified man that is believed by many to be the burial cloth of Jesus Christ. The linen fabric has been radiocarbon dated in 1988 to the Middle Age but a recent robust statistical analysis shows that the resulting age appears flawed by a systematic effect. The present paper discusses the results obtained using innovative dating methods based on the analysis of mechanical parameters (breaking strength, Young modulus and loss factor) and of optochemical ones (FT-IR and Raman). To obtain mechanical results it was necessary to build a particular cycling-loads machine able to measure the mechanical parameters of single flax fibers 1-3 mm long. A least squares multi linear regression (MLR) has been applied to the measured mechanical data estimating a TS age equal to 260 AD. Furthermore, two optochemical methods have been applied to test the linen fabric, obtaining a date of $250 \mathrm{BC}$ by a FT-IR ATR analysis and a date of 30 AD by a Raman analysis. These two dates combined with the mechanical result, weighted through their estimated square uncertainty inverses, give a final date of the Turin Shroud of $90 \mathrm{AD} \pm 200$ years at $95 \%$ confidence level. While this date is both compatible with the time in which Jesus Christ lived in Palestine and with very recent results based on numismatic dating, it is not compatible with the 1988 radiocarbon measurements that should be repeated after the necessary clarifications relative to the possible environmental factors that could have biased the results.
\end{abstract}

Keywords: Turin Shroud, mechanical dating, FT-IR, Raman, opto-chemical dating.

\section{Introduction}

The TS [1,2] (Turin Shroud) is a linen cloth, $4.4 \mathrm{~m}$ long and $1.1 \mathrm{~m}$ wide, that enveloped the dead body of a scourged, thorn-crowned man who was stabbed in the side with a spear and crucified [3]. The TS is believed by many to be the burial cloth in which Jesus Christ was wrapped when his body was placed in a tomb in Palestine about 2000 years ago. Instead others keep on thinking that it is the result of an artist's work and for this reason the TS has generated controversy [4]. In any case the body image visible on the TS (Figure 1) has a great number of peculiar features, impossible to reproduce altogether [4]. For the moment the most credible hypothesis of image formation [4] is based on a burst of energy probably connected with a corona discharge [5]. 
The particular features [6] can be subdivided in two classes: macroscopic and microscopic. To the first class, the following features can be identified. The TS wrapped a human body showing corresponding distortions and rigor mortis, but the image shows no signs of putrefaction. The luminance distribution of both front and back images can be correlated to the clearances between the three-dimensional surface of the body and a covering cloth. The normal tones of light and dark are reversed and the front and back images of the body show almost the same color intensity (yellow-brown). The body image has no well-defined contours and it is visible in areas of non-contact between body and sheet. Its resolution is $4.9 \pm 0.5 \mathrm{~mm}$ and it does not fluoresce when viewed under ultraviolet radiation. The bloodstains, that masked the image forming process, are of human blood frequently surrounded by serum haloes, and are coherent with a draping configuration different from that corresponding to the body image.
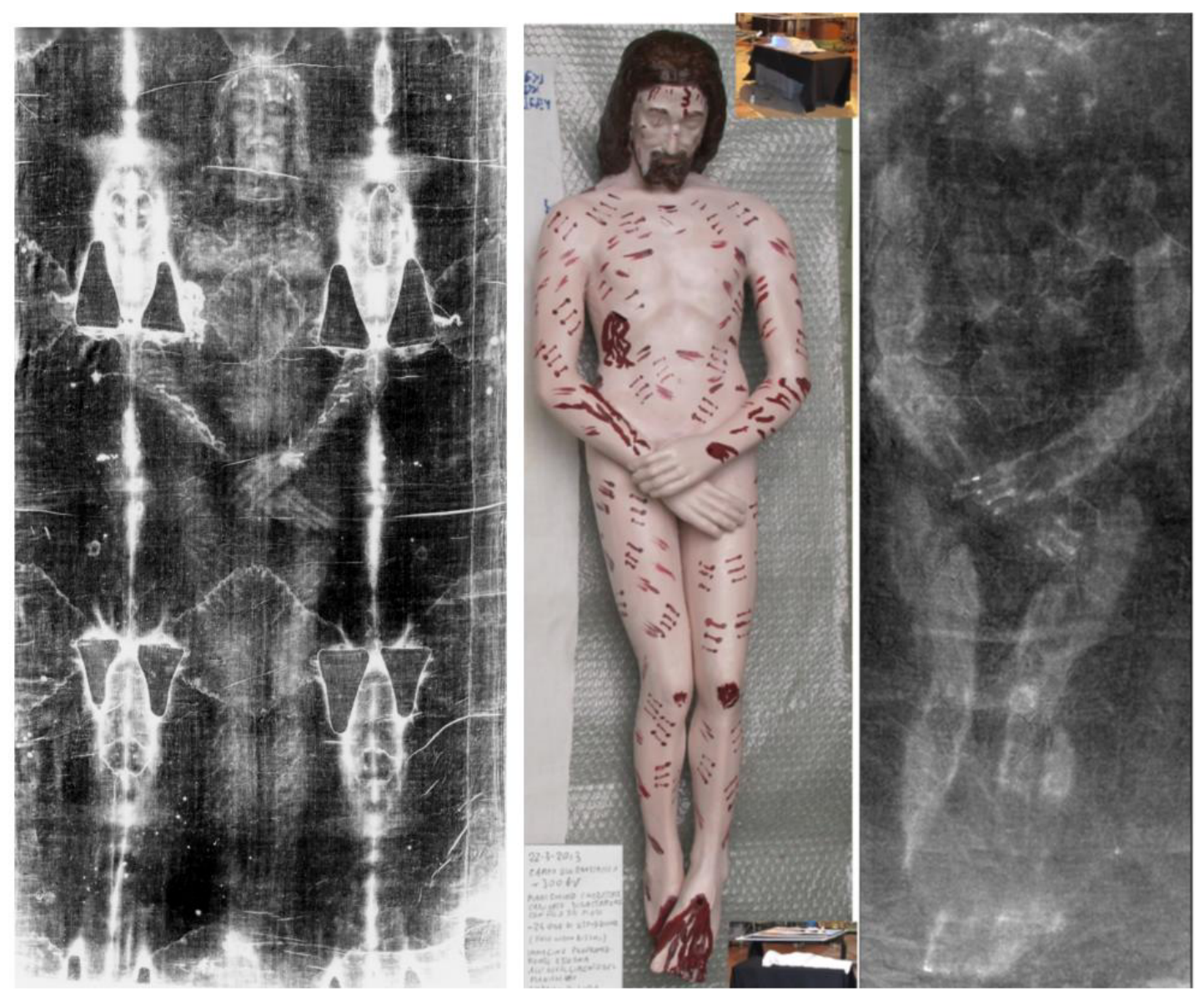

Figure 1. Negative frontal image of the Turin Shroud (on the left), with a corresponding manikin built to produce an experimental image (on the right) by means of Coronal Discharge.

The microscopic features of the TS are the following. The body image is due to chemical reactions of the polysaccharides composing the linen fibers: oxidation, dehydration and conjugation. In contrast to the bloodstains area, there is no cementation between fibers or signs of capillary flow in the image areas. The colored fibers lie only on the uppermost side of the threads, but in some areas the image appears doubly superficial [7]. Color is concentrated in the crevices where two or more threads cross each other, but it is absent under the threads where they cross in the weave of the cloth. Image fibers are adjacent to un yellowed fibers, so striations are evident along the thread. The TS fibers are uniformly colored round their pseudo-cylindrical surface, whereas variations in color intensity can be 
detected along them. Color lies on a 0.2 -micrometer-thick layer interpreted [6] as the primary cell wall of linen: the cellulose of the medulla is colorless.

The linen fabric of the TS has been radiocarbon dated to the Middle Age in 1988 [8], but debates arose over the years. For example a preliminary estimate of the kinetics constants for the loss of vanillin from lignin made by R. Rogers [9] indicated an age for the TS "between 1300 and 3000 years old." A robust statistical analysis [10] applied to the 12 sub-samples used for the 1988 radiocarbon dating has shown that the Medieval result of the TS appears flawed by a significant systematic effect that makes unreliable the assigned data. On the basis of these recent results alternative dating methods of the Relic appear necessary.

The present paper discusses the results obtained for the TS age using innovative methods based on the analysis of mechanical parameters (breaking strength, Young modulus and loss factor) and optochemical ones (FT-IR and Raman).

It must nevertheless be noted that even a date of the TS corresponding to the period in which Jesus Christ was crucified, would not be a sure proof of its authenticity because of the possibility that an ancient cloth was later used by an artist to obtain this body image.

\section{Materials and methods}

From a metrological point of view the definition and the employment of a new reliable dating method needs the satisfaction of the following steps.

a) To experimentally define and measure a bi-univocal property of material that is variable with time, theoretically confirmable and as much as possible independent from other factors like conservation and environmental ones.

b) To have a series of samples of known historical age used to define a mathematical relationship between property of material and time.

c) To evaluate the relationship of Step (b) in terms of bias also due to environmental and conservation factors.

d) To evaluate the relationship of Step (b) in terms of uncertainty that must be lower than a predefined limit; if this limit exceeded, the method must be discharged. In the present case a standard uncertainty [11] lower than 300 years has been accepted.

e) To measure the properties of the sample under test and to estimate its date with the corresponding uncertainty, possibly correcting the bias components.

Notwithstanding that environmental factors, like temperature and humidity, and other factors like contamination with external materials can influence both the mechanical and the opto-chemical parameters of ancient textiles, the methods here adopted show a relatively stable trend if a preselection of fibers, also based on visual inspection and on a particular sampling technique, is done.

In fact if a proper shrewdness is taken into account by means of a preliminary selection of the samples also based on microscopic visual inspection, the bias due to environmental effects can be reduced and therefore a rough dating is possible. The data dispersion reported in the correlation coefficients of the resulting equations seems greatly due to environmental factors that obviously increase the variability of the behavior of the linen fibers, but this dispersion is not so high to prevent a rough dating in the range of some centuries.

Exposition to humidity seems an environmental factor not very influent in the analysis if a proper textile selection is done. This because humidity highly damages the chemical structure, the color and the mechanical behavior of these fibers that therefore are quite simple to recognize and discharge during a preliminary selection.

Exposition of flax textiles to relatively high temperature (about $200{ }^{\circ} \mathrm{C}$ for some hundreds of seconds) can alter the mechanical properties of the fibers thus producing in some cases like FT-IR, bias of hundreds years coupled with a more brownish coloration. Therefore the proposed dating methods have to take into account, as it has been done, for a possible bias due to temperature effects.

A new micro-cycling machine $[12,13]$ has been designed for the measurement of single fibers extracted from flax fabrics. These single fibers, about $1 \mathrm{~mm}$ long have been tabbed on a special self- 
hand-made polyester mask with cyanoacrylate glue and subjected to multiple loading and unloading cycles.

Stresses ranged from zero to $2 / 3$ of the breaking strength with resolution better than about 100 measurement points per cycle. The measured elongation was of $1 \%$ with a resolution of $0.1 \mu \mathrm{m}$; the measured forces ranged from 0 to $0.5 \mathrm{~N}$, with a resolution of $2 \mu \mathrm{N}$.

Raman spectra [14] have been recorded with a Bruker Multiram FT-Raman spectrometer, equipped with a cooled Ge-diode detector. The spectral resolution has been set to $4 \mathrm{~cm}^{-1}$ and the total number of scans for each spectrum to 6000 . The excitation source was a Nd3+-YAG laser at $1064 \mathrm{~nm}$ in the backscattering $\left(180^{\circ}\right)$ configuration. All spectra have been recorded with a laser power of $4 \mathrm{~mW}$.

IR spectra [14] have been recorded with a Nicolet 5700 FT-IR spectrometer, equipped with a diamond attenuated total reflectance (ATR) accessory and a DTGS detector, with a spectral resolution of $4 \mathrm{~cm}^{-1}$. The FT-IR/ATR spectra have been recorded on a single bounce diamond crystal with an area of about $5 \mathrm{~mm}^{2}$, so that the contact size integrates several fibers; the Raman spectra have been recorded on an area of about $0.01 \mathrm{~mm}^{2}$. As the sampling area is relatively small and comprehends few line fibers, various repeatability and reproducibility tests have been performed.

The evaluation of the response intensity of the mechanical and opto-chemical parameters has been made in reference to the natural cellulose degradation as a first order reaction kinetics, such as the radiocarbon decay. Therefore we tried to follow both the mechanical and spectroscopic response by using an exponential law by computing a correlation coefficient with a natural logarithm treatment of all the data. We have also tested other possible relationships between the variables, first of all using a linear model or a polynomial interpolation; the best fitting always resulted the exponential law, thus confirming the agreement between experimental results and kinetical theoretical model. The only exception was found in reference to the mechanical parameter named Loss Factor that showed a linear trend with age. This parameter therefore depends also by other factors also linked to the sliding among the cellulose chains.

Several samples of new and ancient flax textiles coming from different archaeological sites have been analyzed, see Table 1, to calibrate the new dating methods. As the effects of environmental factors, such as temperature and humidity, can change the mechanical and opto-chemical properties, an initial screening was performed in order to choose sufficiently undamaged and not polluted flax fabrics. A preliminary analysis based on visual inspection by means of a stereomicroscope was performed, so as to select only samples suitable for the tests, following some rules defined in [12.13].

The TS dating have been performed using flax fibers sampled from the TS by STURP members; the first Author has their traceability documents that is also reported in Ref. [14]. For example in the case of the mechanical dating, eight different TS fibers, coming from the " $h$ " Filter (corresponding to a dusts vacuumed from the back of the TS in correspondence of the glutes area) have been recognized as such by the first author among others using a petrographic microscope and a particular technique based on cross-polarization [17]. TS fibers in fact present a greater number of transversal defects (kink bands) than other more recent flax fibers and it is therefore relatively easy to detect them.

\section{Mechanical dating}

A multi-parametric mechanical analysis (based on Breaking Strength, two Young Moduli and two Loss Factors) [12] has been considered and used to date the TS.

\subsection{Mechanical Multi-Parametric Dating Method}

In the MMPDM (Mechanical Multi-Parametric Dating Method) 13 reference flax samples have been tested (Table 1); 9 of them have been used for calibration and 3 for testing the fire effects. Sample NI has been successively eliminated from calibration because it was out of the mechanical standards defined for acceptability.

As the TS was subjected to the Chambéry fire in 1532, a study of the fire effects on flax fibers was necessary. The three samples, previously exposed to different heat sources using an oven have been 
used just for this purpose. In the MMPDM the fire effects compatible with the TS features have been estimated to be less than the uncertainty and therefore neglected.

Table 1. List of flax samples used to calibrate the dating methods.

\begin{tabular}{|c|c|c|c|c|c|}
\hline $\begin{array}{c}\text { Samp } \\
\text { le } \\
\text { name }\end{array}$ & Flax sample description & Dating & Provenance & $\begin{array}{l}\text { Method } \\
\text { used }^{\circ}\end{array}$ & $\begin{array}{l}N^{\circ} \text { of single } \\
\text { fibers tested } \\
\text { in MMPDM }\end{array}$ \\
\hline $\mathrm{A}^{*}$ & $\begin{array}{c}\text { New 3:1 twill fabric sized } \\
\text { and bleached }\end{array}$ & 2000 A.D. & $\begin{array}{l}\text { Liotex S.r.L. S. Maurizio } \\
\text { Cavalese, Italy }\end{array}$ & M, F, R & 14 \\
\hline $\mathrm{A} 1 *$ & $\begin{array}{c}\text { New 3:1 twill fabric sized } \\
\text { and bleached, } 200^{\circ} \mathrm{C} \text { heated } \\
\text { for } 300 \mathrm{~s}\end{array}$ & 2000 A.D. & $\begin{array}{l}\text { Liotex S.r.L. S. Maurizio } \\
\text { Cavalese, Italy }\end{array}$ & $\mathrm{M}, \mathrm{F}, \mathrm{R}$ & 5 \\
\hline $\mathrm{A} 2 *$ & $\begin{array}{c}\text { New 3:1 twill fabric sized } \\
\text { and bleached, } 250^{\circ} \mathrm{C} \text { heated } \\
\text { for } 300 \mathrm{~s}\end{array}$ & 2000 A.D. & $\begin{array}{l}\text { Liotex S.r.L. S. Maurizio } \\
\text { Cavalese, Italy }\end{array}$ & $\mathrm{M}, \mathrm{F}, \mathrm{R}$ & 3 \\
\hline B & New $1: 1$ fabric of crude flax & 2000 A.D. & $\begin{array}{l}\text { F.1li Graziano S.p.A., } \\
\text { Mongrando, Italy }\end{array}$ & $\mathrm{M}, \mathrm{F}, \mathrm{R}$ & 15 \\
\hline AII & Paper from a book page & 1800 A.D. & Padua, Italy ${ }^{2}$ & $\mathrm{R}$ & - \\
\hline BII & Paper from a book page & 1746 A.D. & Padua, Italy $^{2}$ & $\mathrm{R}$ & - \\
\hline DII & $\begin{array}{l}\text { Medieval 1:1 fabric } \\
\text { radiocarbon dated }\end{array}$ & $\begin{array}{l}997-1147 \\
\text { A.D. }\end{array}$ & $\begin{array}{c}\text { Cave 38, Qarantal cliff, } \\
\text { east of Jericho, Israel, } \\
\text { IAA }^{3}\end{array}$ & $\mathrm{M}, \mathrm{F}, \mathrm{R}$ & 4 \\
\hline $\mathrm{D}$ & $\begin{array}{l}\text { Medieval 1:1 fabric } \\
\text { radiocarbon dated }\end{array}$ & $\begin{array}{l}\text { 544-605 } \\
\text { A.D. }\end{array}$ & $\begin{array}{l}\text { Coptic from Fayyum, } \\
\text { Egypt, } \mathrm{MA}^{3}\end{array}$ & $\mathrm{M}, \mathrm{F}, \mathrm{R}$ & 6 \\
\hline FII & $\begin{array}{l}\text { 1:1 fabric from a mummy } \\
\text { radiocarbon dated }\end{array}$ & 55-74 A.D. & Masada, Israel, IAA ${ }^{3}$ & $\mathrm{M}, \mathrm{F}, \mathrm{R}$ & 10 \\
\hline NI & $\begin{array}{l}1: 1 \text { fabric from a mummy } \\
\text { radiocarbon dated }\end{array}$ & $\begin{array}{l}220-100 \\
\text { B.C. }\end{array}$ & Lima, Perù, $\mathrm{MM}^{3}$ & $\mathrm{M}$ & 4 \\
\hline NII & $1: 1$ fabric radiocarbon dated & $\begin{array}{l}350-230 \\
\text { B.C. }\end{array}$ & $\begin{array}{c}\text { Cat. 133685-120, Engedi, } \\
\text { Israel, IAA }\end{array}$ & $\mathrm{M}$ & 3 \\
\hline $\mathrm{E}$ & $\begin{array}{l}1: 1 \text { fabric from a mummy } \\
\text { radiocarbon dated }\end{array}$ & $\begin{array}{l}405-345 \\
\text { B.C. }\end{array}$ & $\begin{array}{c}\text { Cat. 2211-CGT 13004, } \\
\text { coll. Drovetti, Egypt, } \\
\text { EET, from } \text { AG }^{3}\end{array}$ & $\mathrm{M}, \mathrm{F}, \mathrm{R}$ & 4 \\
\hline HII & $\begin{array}{l}\text { 1:1 fabric from a mummy, } \\
\text { coming from internal } \\
\text { wrapping }\end{array}$ & $\begin{array}{l}1000-720 \\
\text { B.C. }\end{array}$ & $\begin{array}{l}\text { Cat. 5227, Thebes, Egypt, } \\
\text { EET, from } \mathrm{AG}^{3}\end{array}$ & $\mathrm{M}, \mathrm{F}, \mathrm{R}$ & 3 \\
\hline K & $\begin{array}{l}1: 1 \text { fabric from a curled up } \\
\text { mummy radiocarbon dated }\end{array}$ & $\begin{array}{l}2826-2478 \\
\text { B.C. }\end{array}$ & $\begin{array}{c}\text { Cat. P731-C1, Egypt, } \\
\text { EET }^{3}\end{array}$ & M, R & 3 \\
\hline $\mathrm{MII}^{\wedge}$ & $\begin{array}{l}\text { 1:1 fabric from a mummy, } \\
\text { coming from internal } \\
\text { wrapping }\end{array}$ & 2400 B.C. & $\begin{array}{l}\text { Cat. } 16743, \text { Egypt, EET, } \\
\text { from } \mathrm{AG}^{3}\end{array}$ & $\mathrm{~F}, \mathrm{R}$ & - \\
\hline LII & $\begin{array}{l}\text { 1:1 fabric from a mummy, } \\
\text { coming from internal } \\
\text { wrapping }\end{array}$ & $\begin{array}{l}3500-3000 \\
\text { B.C. }\end{array}$ & $\begin{array}{l}\text { Cat. 278, Egypt, from AG } \\
\text { EET }^{3}\end{array}$ & $\mathrm{M}, \mathrm{F}, \mathrm{R}$ & 3 \\
\hline
\end{tabular}

Notes: Provenance: IAA= Israel Antiquities Authority in Jerusalem, Orit Shamir; EET=Egyptian Museum of Turin, Italy, $\mathrm{MM}=\mathrm{M}$. Moroni, $\mathrm{AG}=\mathrm{A}$. Guerreschi, $\mathrm{MA}=\mathrm{M}$. Alonso.

Being within the assigned historical period, radiocarbon date is reported if available.

$\left(^{\circ}\right)$ M represents the Mechanical Method, F the FT-IR and R the Raman ones. In addition to the samples eliminated by pre-selection some samples were not considered in the calibration because showed evident anomalies like chemical pollution.

$\left({ }^{*}\right)$ Not used for calibration in M and F methods, but for the correction of the detected systematic effect due to fire if any.

$\left({ }^{\wedge}\right)$ Not used for calibration in Raman dating for the high fluorescence.

(1) Sample bought for the purpose of research.

( ${ }^{2}$ Sample of the first author.

$\left(^{3}\right)$ Sample donated for the purpose of research. 
To calibrate the MMPDM only 55 fibers have been considered, since sample A, representing recent flax fabrics as sample B, was not used because treated with Sodium Hydroxide. Thus, due to the chemical effects that produced a mechanical properties variation [12], this sample could not be used.

The data of the 9 samples under test, relative to the parameters [12] Breaking Strength $\sigma_{\mathrm{r}}$, "Final" Young Modulus $\mathrm{E}_{\mathrm{f}}$, "Inverse" Young Modulus $\mathrm{E}_{\mathrm{i}}$, "Direct" Loss Factor $\eta_{\mathrm{d}}$ and "Inverse" Loss Factor $\eta_{i}$, that were independently analyzed through bi-dimensional relationships with age, are reported in Table 2, Figs. 2 and 3. For each of the five parameters in question, the estimated analytical regression values of the calibration curves are reported in Table 3.

The mechanical parameters values measured in correspondence of the TS (glutes area [17]) are reported in the second row of Table 4, Figs. 2 and 3 . Possible bias due to Chamberry fire has been evaluated in advance using Samples A, A1 and A2. To do so, Samples A1 and A2 (see Table 1) have been heated in an oven and tested while Sample A has been assumed as reference specimen (not heated fibers). Sample A1 presents a brownish color level just higher than that of the TS. Corresponding bias has been neglected because smaller than the measurement uncertainty of the mechanical parameters.

A weighted mean for MMPDM has been proposed in [12]. This is based on the weights reported in brackets in the first row of Table 4. A mean date of 372 AD for the TS was obtained (see the third row of Table 4).

Table 2. Mechanical parameter values relative to the historic samples used for calibration.

\begin{tabular}{|l|r|r|r|r|r|}
\hline \multicolumn{1}{|c|}{ Sample } & \multicolumn{1}{|c|}{$\boldsymbol{\sigma}_{\mathbf{r}}[\mathbf{M P a}]$} & \multicolumn{1}{c|}{$\mathbf{E}_{\mathbf{f}}[\mathbf{G P a}]$} & $\mathbf{E}_{\mathbf{i}}[\mathbf{G P a}]$ & $\boldsymbol{\eta}_{\mathbf{d}}[\mathbf{\%}]$ & \multicolumn{1}{c|}{$\boldsymbol{\eta}_{\mathbf{i}}[\mathbf{\%}]$} \\
\hline B & 1076 & 24.8 & 32.2 & $4.8 \%$ & $1.6 \%$ \\
\hline DII & 678 & 19.0 & 23.3 & $5.3 \%$ & $3.3 \%$ \\
\hline D & 63.2 & 4.20 & 5.36 & $7.4 \%$ & $5.2 \%$ \\
\hline FII & 150 & 7.38 & 9.67 & $7.9 \%$ & $3.7 \%$ \\
\hline NII & 119 & 4.55 & $6.88 *$ & $8.0 \%$ & $4.6 \% *$ \\
\hline E HII & 140 & 4.34 & 2.98 & $8.5 \%$ & $3.3 \%$ \\
\hline K & 44.1 & 3.96 & 7.51 & $8.4 \%$ & $5.5 \%$ \\
\hline LII & 58.9 & 5.37 & 6.39 & $9.6 \%$ & $7.0 \% *$ \\
\hline
\end{tabular}

Table 3. Bi-dimensional relations between mechanical parameters and flax's age D.

\begin{tabular}{|c|c|c|}
\hline Property & $\begin{array}{c}\text { Relation between mechanical } \\
\text { property and date D }\end{array}$ & $\begin{array}{c}\text { Pearson coefficient } \\
\text { of interpolated inverse function }\end{array}$ \\
\hline Breaking Strength $\sigma_{\mathrm{r}}[\mathrm{MPa}]$ & $\mathrm{D}=1032 \ln \sigma_{\mathrm{r}}-5095$ & 0.94 \\
\hline Final Young Modulus $\mathrm{E}_{\mathrm{f}}[\mathrm{MPa}]$ & $\mathrm{D}=1407 \ln \mathrm{E}_{\mathrm{f}}-2575$ & 0.91 \\
\hline Inverse Young Modulus $\mathrm{E}_{\mathrm{i}}[\mathrm{MPa}]$ & $\mathrm{D}=1647 \ln \mathrm{E}_{\mathrm{i}}-3466$ & 0.91 \\
\hline Direct Loss Factor $\eta_{\mathrm{d}}[\%]$ & $\mathrm{D}=5450-723 \eta_{\mathrm{d}}$ & 0.95 \\
\hline Inverse Loss Factor $\eta_{\mathrm{i}}[\%]$ & $\mathrm{D}=3707-871 \eta_{\mathrm{i}}$ & 0.90 \\
\hline
\end{tabular}

Table 4. Mechanical parameters measured for the TS and corresponding estimated ages.

\begin{tabular}{|c|c|c|c|c|c|c|}
\hline $\begin{array}{l}\text { Mech. Par. } \\
\text { and weights }\end{array}$ & $\begin{array}{c}\boldsymbol{\sigma}_{\mathbf{r}}[\mathbf{M P a}] \\
\mathbf{( 2 )}^{*}\end{array}$ & $\begin{array}{c}\mathbf{E}_{\mathbf{f}}[\mathbf{G P a}] \\
(\mathbf{1})^{*}\end{array}$ & $\begin{array}{c}\mathbf{E}_{\mathrm{i}}[\mathbf{G P a}] \\
(\mathbf{3})^{*}\end{array}$ & $\begin{array}{c}\boldsymbol{\eta}_{\mathbf{d} \%} \% \mathbf{\%}^{*} \\
(\mathbf{1})^{*}\end{array}$ & $\begin{array}{c}\boldsymbol{\eta}_{\mathbf{i} \%} \% \\
(\mathbf{3})^{*}\end{array}$ & MMPDM \\
\hline Mean Value & 243.22 & 6.28 & 10.78 & 8.2 & 3.6 & - \\
\hline Date AD & 577 & 14 & 456 & -510 & 564 & 372 \\
\hline
\end{tabular}

Note *: the numbers reported in brackets are the coefficient used for the weighted mean used in MMPDM [13]. 


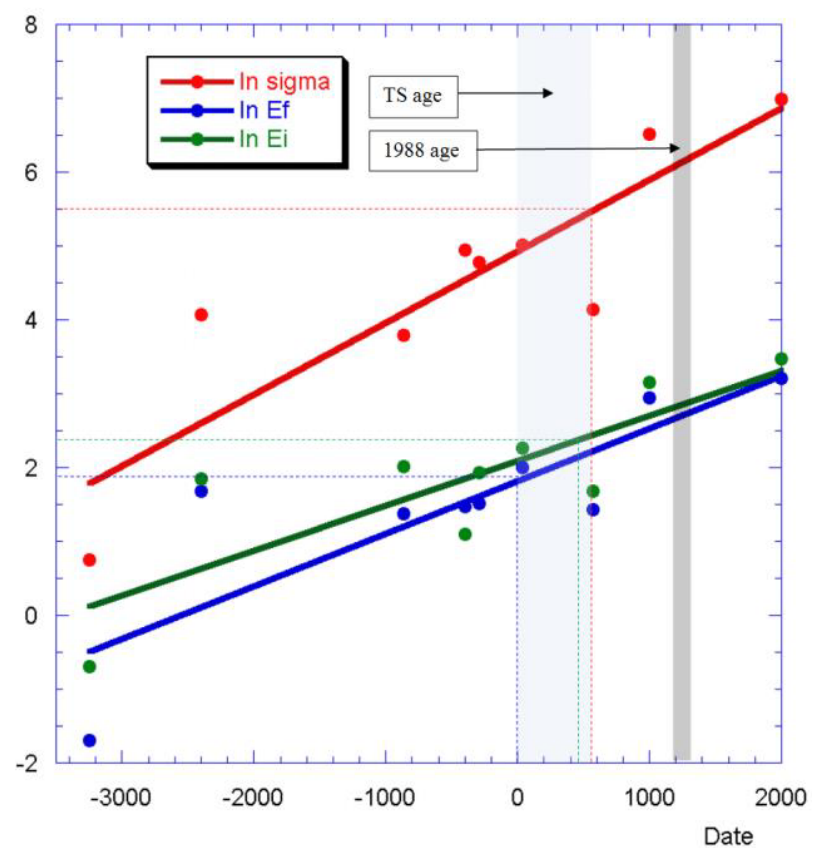

Figure 2. Measured logarithmic values and linear interpolation curve relative to the following mechanical parameters: Breaking Strength (red), Final Young Modulus (blue) and Inverse Young Modulus (green) with the corresponding interpolation curves. The range relative to the TS (light blue bar) date with the corresponding measured values is reported with the range detected during 1988 radiocarbon dating.

\subsection{Multiple Linear Regression for mechanical dating}

A MLR (Multiple Linear Regression) model has been successfully applied to the mechanical parameters in order to obtain a more reliable estimation of the resulting date than the weighted mean proposed in Ref [12] and reported in Table 4. Originally, the applied MLR regression equation was:

$$
d_{i}=\beta_{0}+\beta_{1} \ln \left(\sigma_{r}\right)+\beta_{2} \ln \left(E_{f}\right)+\beta_{3} \ln \left(E_{i}\right)+\beta_{4}\left(\eta_{d}\right)+\beta_{5}\left(\eta_{i}\right)
$$

where $d_{i}$ is the known date value, $\beta_{\mathrm{i}}, \mathrm{i}=0,1, . ., 5$ are the unknown regression coefficients and $\ln$ is the natural logarithm.

The least squares estimate of the unknown regression coefficients was carried out by:

$$
\hat{\beta}=\left(X^{T} X\right)^{-1} X^{T} \underline{d}
$$

Where $\underline{\hat{\beta}}$ is the unknown vector of the estimated regression coefficients, $X$ is the matrix containing the mechanical parameters values and $\underline{d}$ is the known dates vector. A resulting zero determinant value of the matrix product $X^{T} X$ allowed to evidence the existence of a multicollinearity condition for some of the five original mechanical parameters.

For this reason and for mechanical considerations about the physical meaning of the chosen parameters, the number of the parameters has been reduced from five to three, namely Breaking Strength $\sigma_{\mathrm{r}}$, Inverse Young Modulus $\mathrm{E}_{\mathrm{i}}$ and Inverse Loss Factor $\eta_{\mathrm{i}}$. In particular the collinearity was highlighted between the two Young Moduli $\left(\mathrm{E}_{\mathrm{f}}\right.$ and $\left.\mathrm{E}_{\mathrm{i}}\right)$ and between the two Loss Factors $\left(\eta_{\mathrm{d}}\right.$ and $\left.\eta_{\mathrm{i}}\right)$. 


\section{MATEC Web of Conferences}

This fact confirms the validity of the applied regression, since the four parameters in question refer to only two independent mechanical ones. So the MLR model has been simplified as:

$$
d_{i}=\beta_{0}+\beta_{1} \ln \left(\sigma_{r}\right)+\beta_{3} \ln \left(E_{i}\right)+\beta_{5}\left(\eta_{i}\right)
$$

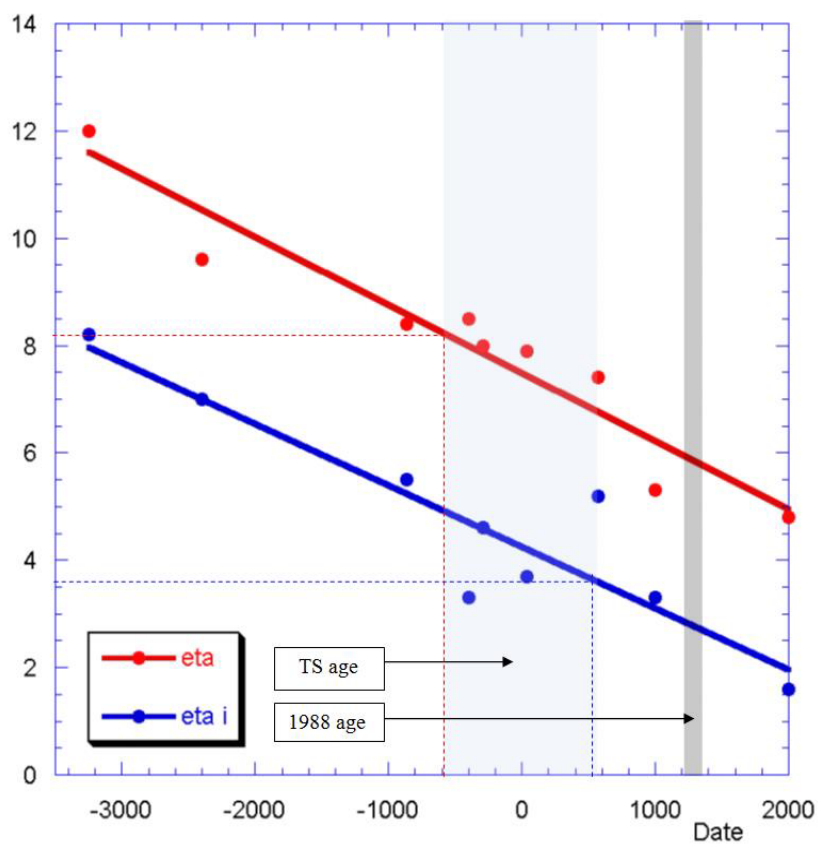

Figure 3. Measured values and linear interpolation curve relative to the following mechanical parameters: Direct loss Factor (red) and Inverse Loss Factor (blue) with the corresponding interpolation curves. The range relative to the TS (light blue bar) date with the corresponding measured values is reported with the range detected during 1988 radiocarbon dating.

At the end of the process, by applying the following formula:

$$
\underline{\hat{e}}=\underline{d}-\underline{\hat{d}}=\underline{d}-X \underline{\hat{\beta}}
$$

the analysis of the date equations residuals contained in vector $\underline{\hat{e}}$ allowed to identify the presence of an outlier in correspondence of the sample $\underline{d}$.

Thus the least squares estimate of the unknown coefficients has been carried out again without the observation characterized by the outlier. Table 5 reports the estimated values of the regression coefficients. Then, the least squares estimated coefficients have been applied to the mechanical data measured on the TS (such data have been put in a row vector, named $\frac{t}{\text { ) }}$; so, by computing the linear regression using Eq. (3), the date of the TS has been finally estimated. Furthermore, by applying the variance propagation law to the variance covariance matrix of the regression terms, computable by:

$$
\Sigma_{\beta \beta}=\sigma_{0}^{2}\left(X^{T} X\right)^{-1} ; \quad \sigma_{0}^{2}=\underline{\hat{e}}^{T} \underline{\hat{e}} /(n-r)
$$

where $\sigma_{0}^{2}$ is the variance factor, $\mathrm{n}$ is the number of samples and $\mathrm{r}$ is the number of the regression coefficients, the variance of the estimated TS date has been obtained, by: 


$$
\sigma_{S}^{2}=\underline{t} \Sigma_{\beta \beta} \underline{t}^{T}
$$

The result is $260 \mathrm{AD}$ with a standard uncertainty [11] of 137 years. This is compatible with the date of $372 \mathrm{AD}$ reported in Table 4, obtained by the MMPDM [13]. The MLR result is certainly more reliable because of the rejection of the outlier.

Table 5. Estimated values of the regression coefficients $\beta_{\mathrm{i}}$ for the MLR, Eq. (1).

\begin{tabular}{|c|c|c|c|c|}
\hline $\begin{array}{c}\text { Regression Coefficient } \\
\text { and (relative property) }\end{array}$ & $\beta_{0}$ & $\beta_{1}\left(\ln \sigma_{\mathrm{r}}\right)$ & $\beta_{3}\left(\ln \mathrm{E}_{\mathrm{i}}\right)$ & $\beta_{5}\left(\eta_{\mathrm{i}}\right)$ \\
\hline Value & 3518 & -409.0 & 723.5 & -75580 \\
\hline
\end{tabular}

\section{Opto-chemical dating}

By means of vibrational spectroscopy, two alternative dating methods have been proposed [14] based on FT-IR and Raman analysis. These techniques exhibit different relationships between the concentration of a molecular species and the measured parameter. Whereas infrared absorbance follows the Lambert-Beer's law, and therefore there exists a linear correlation between absorbance and concentration, the use of Attenuated Total Reflection (ATR) can significantly change this relation being both refraction and absorption indexes changing with wavelength and concentration.

\subsection{FT-IR analysis for dating}

The first method is based on FT-IR ATR analysis. According to the degradation results reported in the literature, many intensity ratios have been examined [14] (Table 6), to obtain a correlation of band intensities versus age. The band integrals more sensible to age resulted those located in the 2600-3080 $\mathrm{cm}^{-1}$ and 3070-3600 $\mathrm{cm}^{-1}$ ranges, whereas those in the $800-1180 \mathrm{~cm}^{-1}$ and in the $1500-1760 \mathrm{~cm}^{-1}$ ranges resulted to have an opposite tendency.

According to Ref. [15], two ratios R1 and R2 (see Eq. 7) of the amplitude peaks integrals of each sample have been evaluated in the corresponding spectra as a function of the wavenumber $\mathrm{n}$ expressed in $\mathrm{cm}^{-1}$ :

$$
\mathrm{R}_{1}=\frac{\int_{2600}^{3080} \mathrm{Idn}}{\int_{1500}^{1760} \mathrm{Idn}} ; \mathrm{R}_{2}=\sqrt{\frac{\int_{2600}^{3080} \mathrm{Idn}}{\int_{800}^{1180} I \mathrm{dn}}} \frac{\int_{3070}^{3600} \mathrm{Idn}}{\int_{1500}^{1760} I \mathrm{dn}}
$$

In Eq. $7 \mathrm{I}$ is the measured FT-IR intensity subtracted to its corresponding baseline, and the integrals are calculated along the indicated wavenumbers. $\mathrm{R}_{1}$ expresses the ratio between $\mathrm{CH}_{1-2}$ stretching and $\mathrm{OH}$ bending while $\mathrm{R} 2$ depends on the product of $\mathrm{CH}_{1-2}$ and $\mathrm{OH}$ stretching divided by the product of $\mathrm{OH}$ bending and other groups contained in the $800-1180 \mathrm{~cm}^{-1}$ range.

Eleven reference flax samples mentioned in Table 1 have been tested, 8 of which have been used for calibration and 3 for testing the fire effects. In the FT-IR method the fire effects compatible with the TS features have been estimated as no negligible and therefore considered as a systematic effect. The data of the historic samples under test are reported in Table 7 and Fig.4. For each of the two ratios in question, the determined calibration curves are summarized in Table 8. 


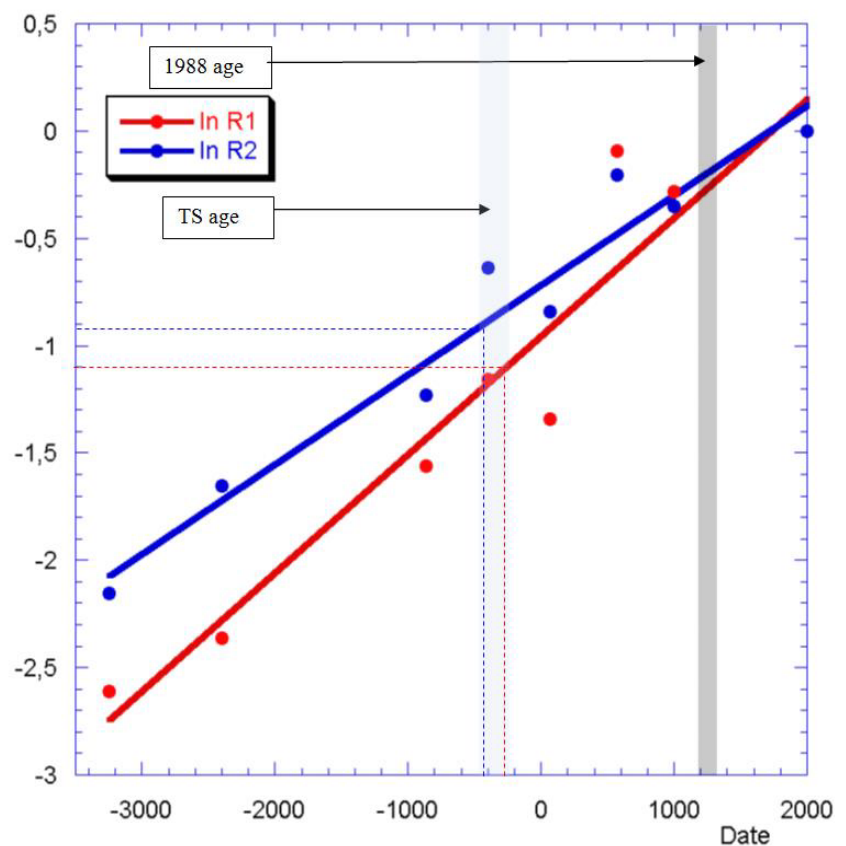

Figure 4. Measured logarithmic values and linear interpolation curve relative to the $\mathrm{R}_{1}(\mathrm{red})$ and $\mathrm{R}_{2}$ (blue) of the FT-IR analysis. The range relative to the TS (light blue bar) date with the corresponding measured values is reported with the range detected during 1988 radiocarbon dating

Table 6. Wavenumbers and interpretation of bands considered in the FT-IR $(*)$ and Raman $(* *)$ analysis.

\begin{tabular}{|c|c|}
\hline Band $\left[\mathbf{c m}^{-1}\right]$ & Description \\
\hline $2995-4000\left(^{*}\right)$ & H-bonded O-H stretching, crystalline and amorphous regions of cellulose \\
\hline $3335\left(^{*}\right)$ & O-H stretching of alcohols establishing weak hydrogen bonds \\
\hline $3305\left(^{*}\right)$ & O-H stretching of hydrogen bonded mainly primary alcohols \\
\hline $3280\left(^{*}\right)$ & O-H stretching of hydrogen bonded mainly secondary alcohols \\
\hline $2900\left(^{*}\right)$ & CH stretching; this band do not show changes as a function of crystallinity \\
\hline $2848-2893\left(^{*}\right)$ & C=O stretching, due to photooxidation \\
\hline $1720-1730\left(^{*}\right)$ & O-H bending \\
\hline $1620-1640\left(^{*}\right)$ & CH ${ }_{2}$ and O-C-H in plane bending, crystalline region of cellulose \\
\hline $1430\left(^{*}\right)$ & C-O-C asymmetric stretching in glycoside linkage; the band decreases with \\
crystallinity
\end{tabular}


Table 7. FT-IR and Raman parameters relative to the historic samples used for calibration.

\begin{tabular}{|c|c|c|c|c|c|}
\hline $\begin{array}{c}\text { Ratios / } \\
\text { Sample }\end{array}$ & Age A.D. & $\mathbf{R}_{\mathbf{1}}{ }^{{ }^{*}}$ & $\mathbf{R}_{\mathbf{2}}{ }^{{ }^{*}}$ & $\mathbf{R}_{\mathbf{R}}{ }^{* * *}$ & Fluorescence $^{* * *}$ \\
\hline A & 2000 & - & - & 1.00 & 0.18 \\
\hline B & 2000 & 1.00 & 1.00 & 0.324 & 1.50 \\
\hline AII & 1800 & - & - & 0.704 & 0.259 \\
\hline BII & 1746 & - & - & 0.554 & 0.204 \\
\hline DII & 1000 & 0.753 & 0.705 & 0.298 & 1.80 \\
\hline D & 575 & 0.910 & 0.815 & 0.430 & 0.96 \\
\hline FII & 65 & 0.261 & 0.432 & 0.317 & 1.49 \\
\hline E & -400 & 0.314 & 0.528 & 0.159 & 1.80 \\
\hline HII & -860 & 0.210 & 0.292 & 0.399 & 1.18 \\
\hline K & -2400 & - & - & 0.143 & 2.40 \\
\hline MII & -2400 & 0.0944 & 0.191 & - & $5.33^{* * *}$ \\
\hline LII & -3250 & 0.0735 & 0.116 & 0.0677 & 1.11 \\
\hline N
\end{tabular}

Notes: $\left(^{\circ}\right)$ this sample was washed and dried before the test.

(*) FT-IR analysis.

(**) Raman analysis.

(***) Sample MII has been eliminated for the high fluorescence.

The FT-IR parameters measured in correspondence of the TS are reported in Table 9. To evaluate possible bias due to Chambéry fire a comparison of the values of Samples A, A1 and A2 was carried out. While Samples A1 and A2 show similar values, Sample A has ratios of $R_{1}$ and $R_{2} 18 \%$ greater. This bias related to environmental factors due to Chambéry fire has been therefore corrected in agreement with this ratio.

Table 8. Bi-dimensional relations among FT-IR and Raman Ratios and flax's age.

\begin{tabular}{|c|c|c|}
\hline Ratio & $\begin{array}{c}\text { Relation between mechanical } \\
\text { property and date } \mathrm{D}\end{array}$ & $\begin{array}{c}\text { Pearson coefficient } \\
\text { of interpolated inverse function }\end{array}$ \\
\hline $\mathrm{R}_{1}{ }^{*}$ & $D=1730+1809 \ln R_{1}$ & 0.899 \\
\hline $\mathrm{R}_{2}{ }^{*}$ & $D=1706+2379 \ln R_{2}$ & 0.949 \\
\hline $\mathrm{R}_{\mathrm{R}}{ }^{* *}$ Low fluorescence, $\mathrm{F}=0.786$ & $D=2451+2299 \ln R_{\mathrm{R}}$ & 0.907 \\
\hline $\mathrm{R}_{\mathrm{R}}{ }^{* *}$ High fluorescence $\mathrm{F}=1.825$ & $D=7498+4871 \ln R_{\mathrm{R}}$ & 0.947 \\
\hline $\mathrm{R}_{\mathrm{R}}{ }^{* *}$ TS fluorescence, $\mathrm{F}=1.55$ & $D=6041+4129 \ln R_{\mathrm{R}}$ & - \\
\hline
\end{tabular}

Notes: $(*)$ FT-IR analysis.

$(* *)$ Raman analysis.

(***) Raman analysis obtained by linear interpolation of curves relative to $\mathrm{F}=0.786$ and 1.55 .

Table 9. FT-IR and Raman parameters measured for the TS and corresponding ages.

\begin{tabular}{|c|c|c|c|}
\hline $\begin{array}{c}\text { Ratios / } \\
\text { Sample }\end{array}$ & $\mathbf{R}_{\mathbf{1}}{ }^{*}$ & $\mathbf{R}_{\mathbf{2}}{ }^{*}$ & $\mathbf{R}_{\mathbf{R}}{ }^{* * *}$ \\
\hline Measured Value & 0.291 & 0.365 & 0.233 \\
\hline Corrected Value* & 0.344 & 0.431 & 0.233 \\
\hline Date AD & -200 & -297 & 32 \\
\hline
\end{tabular}

Notes: $(*)$ FT-IR analysis.

(**) Raman analysis corresponding to a fluorescence ratio of 1.55 . 


\subsection{Raman analysis for dating}

The second method is based on Raman analysis that originally considered five band intensities [14] but finally used the last two reported in Table 6 because they showed to be the most significant for a correlation with a date changing. The band intensity relative to the COC symmetric stretching mode of glicosidic linkage at $1097 \mathrm{~cm}^{-1}$ is the most significant for acquiring information about flax degradation with time; furthermore the hydrogen-bonded $\mathrm{C}-\mathrm{OH}$ band at $3251 \mathrm{~cm}^{-1}$ is quite stable with time. The ratio $\mathrm{R}_{\mathrm{COC} / \mathrm{OH}}$ of the amplitude peaks for each sample have been evaluated through the corresponding spectra:

$$
\mathrm{R}_{\mathrm{R}}=\frac{\mathrm{I}_{1097}}{\mathrm{I}_{3251}}
$$

where I is the measured Raman intensity subtracted to its corresponding baseline, as a function of the wavenumber $\mathrm{n}$ in $\mathrm{cm}^{-1}$.

As reported in Table 1, 14 reference flax samples have been tested, 12 of which have been used for calibration. Furthermore 3 of the reference samples 3 have been used for testing the fire effects. In fact, in the Raman analysis also Sample A was used for calibration because the corresponding spectra resulted to be less sensitive to modern bleaching. While the fire effects, compatible with the TS features, have been estimated to be less than the uncertainty and therefore neglected. The data of the samples under test are reported in Table 7 and Fig. 5 with corresponding fluorescence ratio [14] that turned out to be a not negligible influence parameter. For its relatively high fluorescence (ratio $=5.33$ ), sample MII has been neglected from the Raman analysis.

The Raman parameters measured for the TS, in correspondence of a fluorescence value of 1.55 , are reported in Table 9 and Fig. 5. To evaluate possible bias due to Chambéry fire, a comparison of the values of Samples A, A1 and A2 has been done, but, being less than the uncertainty level, the possible bias was considered negligible.

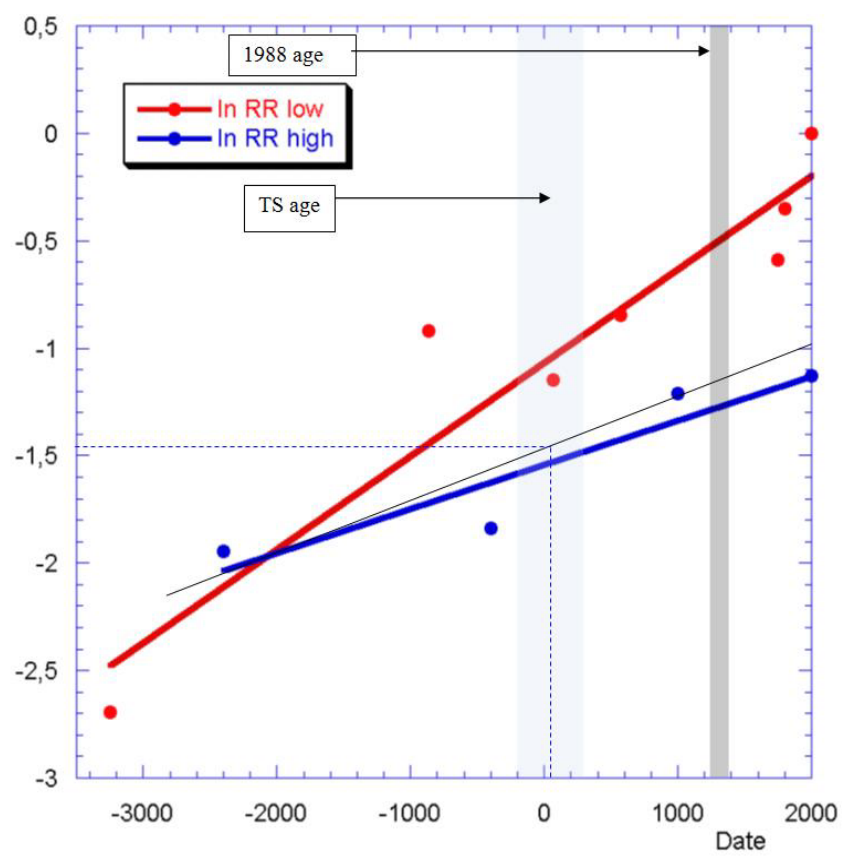

Figure 5. Measured logarithmic values and linear interpolation curve relative to the RR-low fluorescence (red) and R-high fluorescence (blue) of the Raman analysis. The range relative to the TS (light blue bar) date with the corresponding measured values is reported with the range detected during 1988 radiocarbon dating. 
Table 10. TS dating results.

\begin{tabular}{|c|c|c|c|c|c|}
\hline Method & FT-IR** & Raman & $\begin{array}{c}\text { Opto-chemical } \\
\text { (Raman \& } \\
\text { FT-IR) mean }\end{array}$ & Mechanical & $\begin{array}{c}\text { Mean of } \\
\text { Mechanical } \\
\text { and Opto- } \\
\text { chemical }\end{array}$ \\
\hline Date* & $250 \mathrm{BC}$ & $30 \mathrm{AD}$ & $140 \mathrm{BC}$ & $260 \mathrm{AD}$ & $86 \mathrm{AD}$ \\
\hline Standard uncertainty & $200^{* * *}$ & $250^{* * *}$ & 156 & 137 & 103 \\
\hline Expanded uncertainty & 400 & 400 & 312 & 274 & 206 \\
\hline
\end{tabular}

Notes: (*) Rounded to one decade.

(**) Mean value resulting from $\mathrm{R}_{1}$ and $\mathrm{R}_{2}$ of Table 9 .

$(* * *)$ Derived from [11].

\section{Conclusive remarks}

The resulting ages of the TS are reported in Table 10. The expanded uncertainty there indicated has been evaluated at 95\% confidence level in agreement with the ISO GUM [11]; it corresponds to the combined standard uncertainty of the dates multiplied by a coverage factor taken as 2 . The standard uncertainties are relative to variances, covariances and bias if any.

The mean values of the Opto-Chemical dating as FT-IR and Raman analysis have been obtained weighing the measured values by the square uncertainty inverse. First, an Opto-Chemical mean date of $140 \mathrm{BC}$ has been obtained. This value has been successively averaged with the Mechanical result, obtaining the most probable date of the TS to be $86 \mathrm{AD} \pm 206$ years or better $90 \mathrm{AD} \pm 200$ years (having rounded the date to one decade, and the expanded uncertainty to half century). The TS date, preliminarily evaluated in [16] of $33 \mathrm{BC} \pm 250$ years, using a rougher method like MMPDM, that is based on the averaged results coming from independent bi-dimensional least squares regression methods, characterized by an higher uncertainty, is compatible with this new date value.

While this value agrees with the period in which Jesus Christ lived in Palestine, it is not compatible with the 1988 radiocarbon result [8]. The relatively small number of samples used for dating is only indicative of a trend that must confirmed with future analyses; on the other hand also the samples used in the 1988 test were only three and adjacent each other, thus not representative of the whole TS.

This last dating method should be repeated after the necessary preliminary correction for systematic effects relative to the potential environmental factors that could have biased the result, possibly also during the body image formation.

To improve the reliability of the TS dating by the mechanical method, some more analytical investigations can be done. These should consider also some weighting factors of the known regression terms due to the different uncertainty of the flax samples dating. Furthermore, the weighting should be extended also to the mechanical parameters determined for each flax sample. In this way a total least squares procedure could be finally carried out.

An alternative way to improve the obtained results could be to apply an innovative robust procedure so to avoid the definition of the uncertainty distribution that is instead required when a parametric model is applied. Both kind of experiments are let for future works.

Very recent results, based on numismatic dating [15], showing that the TS was seen in the Byzantine Empire starting from $692 \mathrm{AD}$, are further in contrast with the 1988 dating.

\section{Acknowledgements}

This research was carried out with the financial support of the University Research Project-Padova, Italy2009 - \# CPDA099244 entitled: "Multidisciplinary analysis applied to the Shroud of Turin: A study of body image, of possible environmental pollution and of microparticles characterizing the linen fabric". 
Particular thanks to Orit Shamir of Israel Antiquities Authority in Jerusalem, who very kindly furnished many ancient samples of linen fabric, to Egyptian Museum of Turin, Italy, to M. Moroni, A. Guerreschi and to M. Alonso who supplied ancient samples too.

\section{References}

1. Schwalbe, L. A. \& Rogers, R. N. Physics and chemistry of the Shroud of Turin, a summary of the 1978 investigation. Analytica Chimica Acta, Vol. 135, pp. 3-49, (1982).

2. Jumper, E. J. et al. (6 authors). A comprehensive examination of the various stains and images on the Shroud of Turin. ACS Advances in Chemistry, Archaeological Chemistry III: 205, 447-476 (1984).

3. Basso, R. \& Fanti, G. Optics Research Applied to the Turin Shroud: Past, Present and Future. In Gallico, P. V. "Optics Research Trends", Nova Science Publisher Inc., New York, 2007.

4. Fanti, G. Hypotheses regarding the formation of the body image on the Turin Shroud. A critical compendium. J. of Imaging Sci. Technol., Vol. 55, No.6, p. 060507 (Dec 22 2011).

5. Fanti, G. Can Corona Discharge explain the body image formation of the Turin Shroud?. J. of Imaging Science and Technology, Vol. 54, No. 2, March./April 2010, pp. 020508-1/10

6. Fanti, G., Botella, J. A., Di Lazzaro, P., Heimburger, T., Schneider \& Svensson, R. N. Microscopic and Macroscopic Characteristics of the Shroud of Turin Image Superficiality. J. of Imaging Sci. Technol., 54 No. 4, p. 040201-1/8, (2010).

7. Fanti, G. \& Maggiolo, R. The double superficiality of the frontal image of the Turin Shroud. J. of Optics A: Pure and Applied Optics, volume 6, issue 6, 2004, pages 491- 503; www.sindone.info/FANTI.PDF

8. Damon P. E. et al. (21 authors), Nature 337, 611-615 (1989).

9. Rogers, R. N. Studies on the radiocarbon sample from the Shroud of Turin. Thermochimica Acta 425/1- 2, 189-194 (2005).

10. Riani, M., Atkinson, A. C., Fanti, G. \& Crosilla, F. Regression analysis with partially labelled regressors: carbon dating of the Shroud of Turin. Journal of Statistical Computing. Stat Comput DOI 10.1007/s11222-012-9329-5, published online 27 April 2012, http://www.springerlink.com/content/6546174v21304376/

11. BIPM, JCGM 100 (2008) Guide to the expression of uncertainty in measurement.

12. Fanti, G. \& Malfi, P. Multi-parametric micro-mechanical dating of single fibers coming from ancient flax textiles. Textile Research Journal (2013), SAGE Pub., http://dx.doi.org/10.1177/0040517513507366

13. Fanti, G. \& Malfi, P. A New Cyclic-Loads Machine For The Measurement Of Micro-Mechanical Properties Of Single Flax Fibers Coming From The Turin Shroud. AIMETA Congress, Torino, 2013.

14. Fanti, G., Baraldi, P., Basso, R. \& Tinti, A. Non-destructive dating of ancient flax textiles by means of vibrational spectroscopy. Vibrational Spectroscopy (2013), http://dx.doi.org/10.1016/j.vibspec.2013.04.001

15. Fanti, G. \& Malfi, P., The Shroud of Turin Shroud - First Century after Christ!, Pan Stanford Publishing Pte. Ltd., Singapore, 2015.

16. Fanti G., "Optical features of flax fibers coming from the Turin Shroud", 2014 IEEE-ATSI Workshop, Bari, Italy.

17. Fanti, G. \& Basso, R. Statistical Analysis Of Dusts Taken From Different Areas Of The Turin Shroud. Proc. of Shroud Science Group International Conference The Shroud Of Turin: Perspectives on A Multifaceted Enigma, Ohio State University, August 14-17, 2008, Libreria Progetto, Padova, Italy 2009, ISBN 987-88-96477-03-8 http://www.ohioshroudconference.com/papers/p16.pdf 